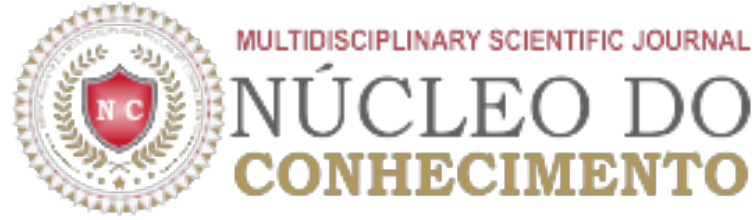

\section{A Propriedade Intelectual na Indústria Fonográfica}

MELO, Sheila de Souza Corrêa de ${ }^{[1]}$, CÂMARA, Vinicius Bogea ${ }^{[2]}$, OLIVEIRA, Natália Bonela de ${ }^{[3]}$

MELO, Sheila de Souza Corrêa de; CÂMARA, Vinicius Bogea; OLIVEIRA, Natália Bonela de. A Propriedade Intelectual na Indústria Fonográfica. Revista Científica Multidisciplinar Núcleo do Conhecimento. Ano 03, Ed. 07, Vol. 01, pp. 5-20, Julho de 2018. ISSN:2448-0959

\section{Resumo}

A indústria fonográfica, ao longo dos anos, sofreu inúmeras e drásticas mudanças. A inovação sempre lhe permeou, ora permitindo dias de glória, ora causando ruptura de paradigmas, o que propiciou debates sobre a proteção de direitos, mas também exigiu que a indústria se reinventasse. Os direitos de propriedade intelectual sempre fizeram parte da história da indústria da música, muitas vezes utilizados como vantagens competitivas e, outras vezes, impedindo que terceiros se aproveitassem indevidamente dos esforços de seus titulares. O objeto de presente estudo, que apresenta uma pesquisa descritiva exploratória sobre o tema, com análises de casos, busca levantar dados sobre o uso e aplicação dos principais instrumentos de propriedade intelectual, no âmbito da Indústria Fonográfica, numa analise crítico-reflexiva sobre o atual cenário da inovação, sobretudo sob o viés do novo modelo de consumo de música.

Palavras-chave: Instrumentos de Propriedade Intelectual, Ativos Intangíveis, Indústria Fonográfica, Indústria da Música.

\section{Introdução}

A indústria fonográfica, composta por empresas responsáveis pela gravação, edição e distribuição de mídia sonora, talvez seja a indústria mais influenciada pelas inovações tecnológicas da última década, sobretudo as relativas aos novos métodos de disponibilização e consumo de música. As reconfigurações na oferta de produtos, serviços e nas relações entre produtores, artistas e consumidores se verificou no campo da música através da constituição de um espaço aberto, múltiplo e interativo que reordenou a lógica de distribuição e controle de grandes gravadoras. Contudo, essa mesma reconfiguração tem como efeito uma maior vulnerabilidade no que concerne às práticas de gestão e controle de direitos de propriedade intelectual, como sugerido Dias (2010). 
Desde o início dos anos 2000, as relações entre novas tecnologias digitais e produção e consumo de música vem se intensificando e algumas alternativas de engenharia e economia que entrelaçam direitos de propriedade intelectual, consumo cultural e difusão cultural vem se notabilizando e compondo parte das experiências sociais de contato com a música, a exemplo dos canais de streaming para smartphones, por exemplo. Só esse formato de consumo produziu em 2015 um crescimento de 3,2\% no faturamento da indústria fonográfica, feito inédito desde 1998 (THE ECONOMIST, 2016).

Se levarmos em consideração o papel desempenhado pela informação na sociedade contemporânea, tal como sugerido por Marchi (2006, p 173), é preciso refletir sobre o lugar da indústria e as alternativas para preservação de direitos sobre obras em um contexto de conectividade e fluxo ao qual a tecnologia parece estar adequada, mas que ainda oferece sensíveis desafios à legislação internacional de propriedade intelectual. Essas dificuldades atingem inclusive a própria conceituação do escopo, extensão e limites da categoria de propriedade intelectual, contudo, seguindo as orientações da Organização Mundial de Propriedade Intelectual, tomamos aqui seu caráter exemplar e a possibilidade de agrupamento dos produtos e processos nela enquadrados para a compreensão do fenômeno contemporâneo de consumo de conteúdo musical face ao instrumental que tipifica o conteúdo em três (ou mais) grandes categorias de reconhecimento e garantia de direitos (direitos autorais, propriedade industrial e proteção "sui generis") que tem como principal eixo de identificação a responsabilidade e o reconhecimento sobre a criação (individual e pessoal no primeiro, coletivo e privado no segundo, coletivo e comunitário, no terceiro).

No presente trabalho, não há a o anseio de exaurimento de todos os conceitos dos ativos de propriedade intelectual ou de todas as questões que envolvem as inovações na indústria fonográfica, contudo, objetivase analisar como as principais modalidades podem ser utilizadas e aplicadas ao frequentemente reinventado mundo da música.

\section{A propriedade intelectual na indústria fonográfica}

\subsection{Marca}

Marca pode ser conceituada como sendo um sinal distintivo, visualmente perceptível, que identifica um produto ou serviço. Também pode ser definida como sinal característico atribuído de forma facultativa a produtos e serviços para identificá-los e diferenciá-los de outros do mesmo gênero ou espécie (DI BLASI, 2003, P.115).

Para Kotler (1999, p.233):

Uma marca é um nome, termo, sinal, símbolo ou desenho, ou uma combinação dos mesmos, que pretende identificar os bens e serviços de um vendedor ou grupo de vendedores e diferenciá-los dos concorrentes. Um nome de marca é aquela parte da marca que pode ser pronunciada ou pronunciável.

Como indica Moreira (2006, p. 17), "as marcas foram evoluindo de forma gradativa e permanente, desde suas primeiras manifestações nas fases primitivas até as formas mais complexas de hoje em dia, em decorrência das necessidades materiais do homem", nota-se que a própria noção de marca evolui juntamente com o ser humano.

De forma natural, as marcas evoluíram, também, com a indústria fonográfica, passando não somente a 
identificar os produtos ou serviços a ela inerentes, mas constituindo importantes ativos intangíveis para as empresas, que podem licenciá-las e transacioná-las, além de servir de base para operações de fusão ou aquisição, securitização ou garantias de empréstimos, como sugerem Reilly e Schweihs (1998, p. 57).

Cumprindo sua função primordial e principal, alguns exemplos podem ser dados de marcas que identificam importantes serviços e produtos da indústria fonográfica, dentre as quais as que identificam autores, bandas, intérpretes, gravadoras, fabricantes e empresas de modo mais amplo.

Caso particular na constituição de marcas é o Spotify, uma empresa especializada em dar acesso a milhões de músicas, em formato digital, através da tecnologia streaming. Pioneira em apostar no consumo de música on-line, a Spotify, sozinha, vale mais que toda indústria de música dos EUA, conforme o Wall St Journal: "o valor líquido do Spotify alcançou US\$ 8,4 bilhões, mais que o dobro do Pandora, seu rival mais próximo, com cerca de US\$3,5 bilhões”.

Sobre o caso Spotify, destaca-se a importância dada ao registro das marcas pela companhia SPOTIFY $\mathrm{AB}$, que buscou proteção em diversas classes de produtos e serviços, especificando-os pormenorizadamente, na busca de amparar toda a atuação da empresa, junto ao Instituto Nacional da Propriedade Industrial (INPI): 
Revista Científica Multidisciplinar Núcleo do Conhecimento - RC: 16703 - ISSN: 2448-0959

https://www.nucleodoconhecimento.com.br/administracao/propriedade-intelectual

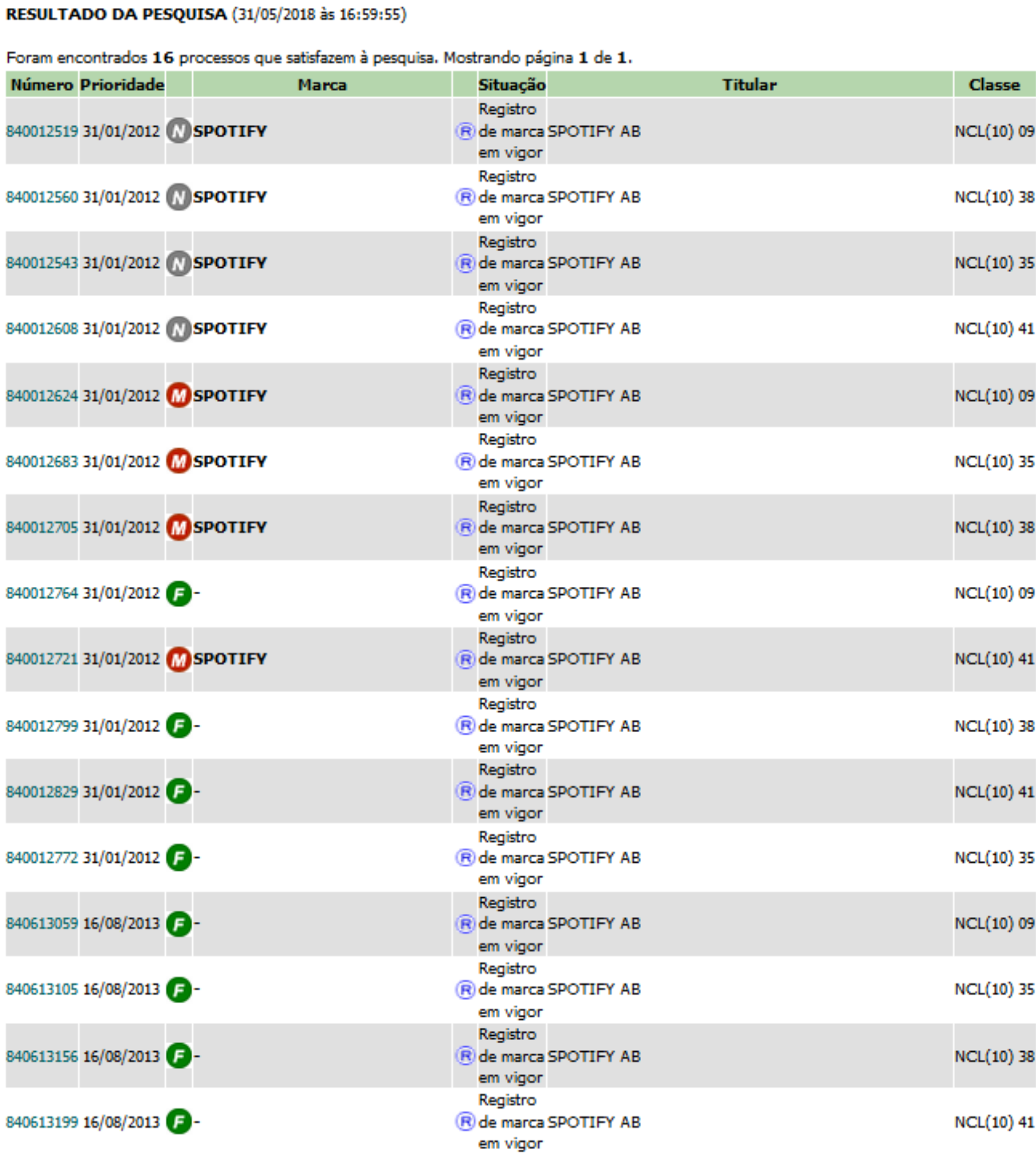

Páginas de Resultados:

1

Figura 1: Registros de marca feitos pela Spotify AB. Fonte: Base de dados do INPI

Curiosamente, a empresa não protegeu a marca na classe 42 (para serviços relacionados a software), 
como fizeram suas concorrentes Apple Music (processo 909585792) e Pandora (processo 907934439) e empresas de streaming de vídeos, como o Youtube (registros 828594643 e 828594465) e Vimeo (registro 830987819).

Sobre a amplitude de proteção para produtos e serviços, é importante destacar que artistas e empresas também utilizam a força de suas marcas de sucesso para dar nome a produtos não necessariamente vinculados à indústria da música. Isso mostra que o poder da música vai além dela própria, determinando padrões de consumo em outras searas do mercado, emprestando-lhes seus valores, sensações, sua atitude e seu comportamento.

O contrário também acontece. Diversas marcas pré-estabelecidas e de sucesso promovem parcerias com empresas do mundo da música ou artistas, para promoção de suas vendas conjuntas. Por todo o acima, percebe-se a importância que as marcas têm para o setor fonográfico, seja na identificação de seus produtos e serviços, seja para valorização da empresa, que pode valer-se delas para formar parcerias, licenciá-las, cedê-las e comercializá-las, constituindo, assim, verdadeiros pilares da economia.

\subsection{Patente}

Patentes de Invenção são definidas como sendo um título de direito temporário concedido pelo Estado para conferir ao titular da invenção o direito de impedir que terceiros explorem ou usem, sem o seu consentimento, o objeto de sua patente e/ou processo ou produto, obtido por meio de um procedimento previsto em lei.

$\mathrm{Na}$ Indústria fonográfica, um ambiente tecnológico de altíssima competitividade, o monitoramento das tecnologias patenteadas ou em processo de patenteamento, pode ser uma interessante fonte de informação sobre tendências tecnológicas. Além disso, a proteção de inventos por parte dos atores da indústria fonográfica pode lhes garantir o direito de impedir que terceiros se aproveitem indevidamente de seus esforços, pesquisa e desenvolvimento, ou, até mesmo, ser um instrumento valioso, apto a ser transferido, negociado ou licenciado por seu titular, na medida em que determina, de forma clara, a data de início e fim da proteção e o conteúdo da invenção.

\subsection{Software}

Como dito anteriormente, o software, no Brasil, é considerado um direito de cunho autoral, porém, será tratado em tópico apartado, em função de suas peculiaridades previstas na lei 9.609 (BRASIL, 1998) e outros dispositivos, bem como a disparidade de tratamento dado por outros países, que, a exemplo dos Estados Unidos, protegem os softwares como patente.

Segundo o mesmo dispositivo jurídico, entende-se como software o sistema de linguagem natural ou codificada ajustado a um suporte e que permite a manipulação e manuseio de informações com base em técnica digital ou análoga (BRASIL, 1998). Seu registro pode ser feito junto ao INPI, podendo ou não ser sigiloso, isto é, o software pode ser registrado sem que seja revelado o seu conteúdo de programação. O INPI atua como fiel depositário do software, que somente poderá ser revelado através de mandado judicial, para que se promova uma perícia técnica, nos termos do Art. $4^{\circ} . \S 3^{\circ}$ e $4^{\circ}$ da Instrução Normativa $\mathrm{n}^{\mathrm{o}}$ 11-2013 do INPI. 
Cumpre ressaltar que o software, como todo direito autoral, não requer registro, embora seja recomendado a fim de que se possa comprovar sua autoria e data de criação, dentre outras vantagens. $\mathrm{O}$ direito de explorá-lo economicamente perdura por 50 anos a contar de $1^{\circ}$ de janeiro do ano subsequente ao de sua publicação ou, na falta de publicação, da data da sua criação, na forma do parágrafo $2^{\circ}$ do Art. 10 da Lei 9609/98.

Os softwares estão presentes na indústria fonográfica na captação dos sons; na mixagem, a partir de consoles e mesas computadorizadas; dentro de instrumentos musicais a exemplo dos teclados e sintetizadores; na edição dos fonemas, que permite a manipulação dos sons podendo captar e inserir efeitos e até mesmo corrigir ruídos, a exemplo do "autotune".

Nota-se que o software, além de ser uma ferramenta indispensável na produção musical, pode ser considerado, no conjunto aqui apresentado, o instrumento de maior proximidade com o público nos dias atuais, sobretudo pelo modo como afeta os padrões de consumo da música.

Os softwares de compartilhamento de arquivos e os softwares inseridos nos dispositivos tocadores de música digital foram responsáveis por uma verdadeira quebra de paradigma da indústria fonográfica. Inventado na Coreia do Sul em 1998 pela Saehan, o primeiro MP3 do mundo se chamava MPMan (ADNER, 2012). A partir daí várias empresas começaram a produzir aparelhos com softwares de reprodução de músicas em formato digital, mas, somente com o surgimento dos Ipods é que a tecnologia ganhou força e passou a ser objeto de desejo dos consumidores. Tais inovações podem ter trazido prejuízos à indústria fonográfica tradicional, mas inauguraram o que se pode chamar de uma nova era para a indústria fonográfica, além de proporcionar aos consumidores um acesso quase que ilimitado ao conteúdo musical mundial.

O exemplo mais icônico desta ruptura foi a criação do Napster, um programa em rede não centralizada de troca de arquivos, mediante acesso direto a determinados arquivos armazenados em outras máquinas que também estão conectadas à rede e ao software no qual usuário desempenhava a função de servidor e também de consumidor. No início de 2001, a Napster vivia o seu apogeu, com mais de 8 milhões de usuários conectados trocando diariamente uma média de 20 milhões de canções, mas não resistiu a várias ações judiciais impetradas por gravadoras e bandas sob acusações de violação aos seus direitos autorais, conforme analisado por Lima e Santini (2004, p. 10).

O programa mais popular de compartilhamento de arquivos é considerado o mote do declínio do mercado fonográfico. A experiência de acessar música por meio da Internet atraiu os programadores, aproximandoos aos consumidores, constituindo um processo inovador consistente de difusão e de consumo de música. Apesar de ter perdido a "guerra" em 2001, o caso Napster abriu portas para outros softwares de compartilhamento, inclusive os de consumo streaming. O surgimento destas inovações alterou o antigo equilíbrio entre os consumidores, os intermediários da indústria e os donos dos direitos autorais. Consequentemente, a crescente utilização destes tipos de software tem provocado o judiciário e, naturalmente, a legislação deverá surgir para preencher as lacunas do sistema de proteção.

\subsection{Direito autoral}

Direitos autorais são, talvez, os ativos de propriedade intelectual mais debatidos e litigados da indústria fonográfica, podendo ser definidos como: 
O conjunto de prerrogativas que a lei reconhece a todo criador intelectual sobre suas produções literárias, artísticas ou científicas, de alguma originalidade: de ordem extra pecuniária, em princípio, sem limitação de tempo; e de ordem patrimonial, ao autor, durante toda a sua vida, com o acréscimo, para os sucessores indicados na lei, do prazo por ela fixado (CHAVES, 1995. p. 28).

Os direitos autorais podem ser direitos do autor (autores e editoras) e conexos (intérpretes, músicos e gravadoras) e sua proteção independe de registro, porém, ao promover o registro, é possível comprovar a autoria e determinar a data da criação. As obras musicais e fonemas podem ser registrados na Escola Nacional de Música (Universidade Federal do Rio de Janeiro) ou na Fundação Biblioteca Nacional (junto EDA, seu Escritório de Direito Autoral).

Os direitos autorais dividem-se em direitos morais e patrimoniais. Os direitos morais são de natureza pessoal e ordem personalíssima do autor, recaindo sobre a divulgação, alteração, e, sobretudo o direito de resguardar a autoria. Segundo o ECAD:

Os direitos morais asseguram a autoria da criação ao autor da obra intelectual, no caso de obras protegidas por direito de autor. Já os direitos patrimoniais são aqueles que se referem principalmente à utilização econômica da obra intelectual. É direito exclusivo do autor utilizar sua obra criativa da maneira que quiser, bem como permitir que terceiros a utilizem, total ou parcialmente.

Ao contrário dos direitos morais, que são intransferíveis e irrenunciáveis, os direitos patrimoniais podem ser transferidos ou cedidos a outras pessoas, às quais o autor concede direito de representação ou mesmo de utilização de suas criações. Caso a obra intelectual seja utilizada sem prévia autorização, o responsável pelo uso desautorizado estará violando normas de direito autoral, e sua conduta poderá gerar um processo judicial.

Os Direitos Patrimoniais, portanto, são aqueles que os autores podem licenciar às empresas, gravadoras, em sua maioria, para a música possa ser reproduzida, editada, adaptada, traduzida, distribuída, interpretada, executada, sendo que, jamais poderá abdicar de ser reconhecido como autor. Os direitos patrimoniais decaem com o advento do prazo de setenta anos após a morte do autor, segundo a Lei $\mathrm{n}^{\circ}$ 9.610/98, porém, os direitos morais jamais podem deixar de serem reconhecidos.

O Escritório Central de Arrecadação e Distribuição (ECAD) é a entidade responsável pela arrecadação e distribuição dos direitos autorais no Brasil. É administrado por nove associações de gestão coletiva que nasceram para gerir os direitos dos autores, fazer o recolhimento e distribuir os valores em todo o país, representando, assim, milhares de artistas filiados.

Os direitos autorais de obras musicais e fonogramas podem ser exercidos diretamente por seus titulares, ou geridos coletivamente pelo ECAD, e a disponibilização pública não autorizada desse tipo de conteúdo - inclusive para download - foi inserido no artigo 184 código penal brasileiro.

Não é necessário que o autor pertença a uma das nove associações para ter preservados e garantidos seus direitos, podendo administrar por conta própria os direitos de seu repertório, mas a gestão coletiva facilita aos usuários de música receberem uma autorização ampla e única para execução de qualquer obra musical protegida e cadastrada no banco de dados do ECAD e das associações de música. 
De fato, com o aumento significativo do consumo de música, provocado pelo uso de tecnologias já abordadas nos tópicos anteriores, sobretudo o streaming deveria, também, aumentar os valores arrecadados e sua distribuição aos titulares patrimoniais da obra. Tal fato não vem ocorrendo.

$\mathrm{Na}$ verdade, esta é uma questão extremamente debatida. Artistas pedem transparência na arrecadação, empresas de streaming pedem paciência e as gravadoras e editoras também questionam direitos.

\subsection{Desenho industrial}

No Brasil, com a promulgação da Lei 9.279/96, o Desenho Industrial passou a ser protegido através de registro próprio. Porém, assim como no caso dos softwares, alguns países (como os Estados Unidos) o protegem a título de patente.

O registro de Desenho Industrial (DI) protege, conforme o INPI "a configuração externa de um objeto tridimensional ou um padrão ornamental (bidimensional) que possa ser aplicado a uma superfície ou a um objeto. Ou seja, o registro protege a aparência que diferencia o produto dos demais". Ressalte-se que não podem ser protegidos como DI "funcionalidades, vantagens práticas, materiais ou formas de fabricação, assim como também não se pode protege cores ou a associação destas a um objeto” (INPI, 2015).

Não podemos afirmar que o design dos produtos inerentes à Indústria Fonográfica não tenha sido importante, desde o surgimento dos primeiros produtos e dispositivos para o consumo de música, porém, uma empresa, especificamente, pode ser responsabilizada pelo "glamour" que revolucionou a história dos players de música: a Apple. Para a Apple, o desenho industrial sempre foi o principal foco dos produtos, não obstante terem excelente sucesso nas performances de seus produtos, por seus softwares e hardwares incrivelmente inovadores. O desenvolvimento de qualquer aparelho da Apple sempre começa pelo design e testes de usabilidade (facilidade de uso). Só depois desta etapa o produto é enviado para o setor de hardware, responsável pela montagem daquilo que a equipe de design solicita. Essa preocupação se torna latente mesmo quando iniciou-se o processo de declínio de um dos principais produtos comercializados pela empresa (o Ipod) frente a popularização dos serviços de streaming.

O design continuou sendo importante não só para a venda de produtos, mas também para a criação de padrões de consumo e até mesmo "fãs" fiéis a determinadas marcas ou linha de produtos da indústria fonográfica. Entretanto percebe-se que, nos dias atuais, os produtos são desenvolvidos para suprir diversas necessidades, de forma multifuncional: ouvir música na TV, assistir a um vídeo no celular, gravar uma música através de computadores pessoais, em ambientes domésticos, promover os temas através de redes sociais, etc.

Ora, o desenho industrial, enquanto ativo de propriedade imaterial, é pensado para produtos que possuem inúmeras funcionalidades. À medida em que se restringem os dispositivos necessários para todas estas funções, aumenta-se o desafio do designer, que deve pensar na praticidade e, principalmente, na sua atratividade.

\subsection{Topografia de circuito integrado}

Conforme o INPI, "Topografias de circuitos integrados são imagens relacionadas, construídas ou codificadas sob qualquer meio ou forma, que represente a configuração tridimensional das camadas que 
compõem um circuito integrado. Em outras palavras, é o desenho de um chip". O capítulo III da Lei 11.484, de 31 de maio de 2007, estabelece como se dá a proteção à propriedade intelectual das topografias de circuitos integrados. Sua proteção é conferida pelo prazo de 10 (dez) anos da data do depósito ou da $1^{\text {a }}$ exploração (o que ocorreu primeiro).

Os circuitos integrados são nada mais do que Chips. Esses circuitos integrados, dentre outras coisas, são usados em memórias ou processadores e dispositivos como chips de celulares, chips de Smarphones, placa-mãe e memória RAM de computadores, MP3 Players, além de aparelhos como Televisores Digitais e Tablets, dentre outros, para realizar funções eletrônicas em equipamentos, por exemplo, com microprocessadores e memória (JUNGMANN; BONETTI, 2010).

Sendo assim, foram e ainda são de imenso valor para a indústria fonográfica, pois sem eles não seria possível o processamento de algumas funções indispensáveis aos processos de gravação e edição de música, armazenamento de dados, bem como as tecnologias "smart" que permitem o consumo de música straming, dentre outras.

\section{Instrumentos de propriedade intelectual não aplicados à indústria fonográfica}

\subsection{Indicação geográfica}

O termo Indicações Geográficas foi inaugurado na Lei da Propriedade Industrial 9.279/96 sendo ali definido, em seu Art. 176 "indicação geográfica a indicação de procedência ou a denominação de origem”, que por sua vez são definidos pelos Art. 177 "Considera-se indicação de procedência o nome geográfico de país, cidade, região ou localidade de seu território, que se tenha tornado conhecido como centro de extração, produção ou fabricação de determinado produto ou de prestação de determinado serviço" e Art 178 "Considera-se denominação de origem o nome geográfico de país, cidade, região ou localidade de seu território, que designe produto ou serviço cujas qualidades ou características se devam exclusiva ou essencialmente ao meio geográfico, incluídos fatores naturais e humanos.”.

Até os dias atuais, não houve nenhum pedido de Indicação Geográfica relacionado à indústria fonográfica, entretanto, o Art. 177 dá abertura à prestação de serviços, desde que o nome geográfico de país, cidade, região ou localidade de seu território, que se tenha tornado uma referência. Recentemente o Brasil concedeu sua primeira Indicação de Procedência a um tipo de serviço: o porto digital (LACERDA, 2012)

Desta forma, mesmo não sendo um direito de propriedade intelectual aplicado à Indústria Fonográfica, não há impedimentos a que, em algum momento, haja o notório reconhecimento de determinada região, estado ou cidade como referência em determinado serviço relacionado à fonografia.

\subsection{Cultivares}

No Brasil, são passiveis de proteção as novas cultivares ou a cultivares essencialmente derivadas, de quaisquer gêneros ou espécie vegetais, bem como as que já tenham sido oferecidas à venda até a data do pedido, obedecidas algumas condições cumulativas, previstas no Art. $4^{\circ}$ da Lei $n^{\circ} 9.456$ (BRASIL, 1997).

A proteção das cultivares dura 15 anos, a partir da data de concessão do Certificado Provisório de 
Proteção “com exceção das videiras, árvores frutíferas, árvores florestais e árvores ornamentais, inclusive, em cada caso, o seu porta-enxerto, para as quais a duração será de 18 anos”, conforme o Ministério da Agricultura (BRASIL, 1997).

Os cultivares também não são objetos de proteção relacionada à indústria fonográfica, pois, a tutela do bem protegido não guarda afinidade com o mercado da música.

\section{Conclusão}

Ao longo do trabalho, pôde-se entender que a indústria fonográfica se vale da maioria dos direitos de propriedade intelectual abordados. Nota-se que a evolução de seus mecanismos, produtos, modelos de negócio e serviços, ao longo dos anos, fez com que o consumo de música fosse progressivamente sendo democratizado.

Graças às inovações da última década, com a popularização da internet, o surgimento dos formatos digitais de música, bem como as formas de compartilhamento de tais mídias, o consumo de CDs lançados por gravadoras tornou-se obsoleto o que fez com que a indústria da música entrasse em declínio, sendo obrigada a encontrar formas de se adequar e se reinventar, diante dos novos padrões de comportamento e consumo.

As mudanças causaram debates sobre os conflitos entre a oferta de cultura à sociedade e a devida remuneração dos titulares de direitos autorais e seus agentes e intermediários. Mais do que nunca se deve pensar em um novo modelo de gestão dos direitos e reforma do ordenamento jurídico, para reconciliar o direito dos autores (e demais atores da indústria fonográfica) com o direito dos consumidores, já habituados ao ambiente livre da música on-line, via consumo streaming.

\section{Referências}

ADNER, Ron. Tradutor: ARAUJO, Alessandra Mussi. Sob a lupa da inovação. Rio De Janeiro: Campus, 2012

BRASIL. Decreto-Lei n ${ }^{\circ} 2.848$, de 7 de setembro de 1940. Código Penal Brasileiro. Brasília: Secretaria da Casa Civil, 1940. Disponível em <http://www.planalto.gov.br/ccivil_03/decretolei/Del2848compilado.htm> Acesso em 31 de mai. de 2018.

BRASIL. Lei no 9.279, de 14 de maio de 1996. Lei de propriedade industrial. Brasília: Secretaria da Casa Civil, 1996. Disponível em <http://www.planalto.gov.br/ccivil_03/Leis/19279.htm> Acesso em 31 de mai. de 2018.

BRASIL. Lei $n^{\circ}$ 9.456, de 25 de abril de 1997. Lei de proteção de cultivares. Brasília: Secretaria da Casa Civil, 1997. Disponível em <http://www.planalto.gov.br/ccivil_03/LEIS/L9456.htm> Acesso em 31 de mai. de 2018.

BRASIL. Lei no 9.609, de 19 de fevereiro de 1998. Lei de Software. Brasília: Secretaria da Casa Civil, 1998. Disponível em <http://www.planalto.gov.br/ccivil_03/leis/19609.htm> Acesso em 31 de mai. de 2018. 
BRASIL. Lei n ${ }^{\circ}$ 9.610, de 19 de fevereiro de 1998. Lei de direitos autorais. Brasília: Secretaria da Casa Civil, 1998. Disponível em <www.planalto.gov.br/ccivil_03/Leis/L9610.htm> Acesso em 31 de mai. de 2018.

BRASIL. Lei nº11.484, de 31 de maio de 2007. Lei de Topografia de Circuitos Integrados. Brasília: Secretaria da Casa Civil, 2007. Disponível em http://www.planalto.gov.br/ccivil_03/_ato2007-2010/2007/lei/111484.htm> Acesso em 31 de mai. de 2018.

DIAS, Marcia Tosta. Indústria fonográfica: a reinvenção de um negócio. Economia da arte e da cultura. Bolaño, Golin e Brittos (orgs.). SP: Itaú Cultural, 2010. P. 165-183.

ECAD. “O que é direito autoral?”. Disponível em <http://www.ecad.org.br/pt/direito-autoral/o-que-edireito-autoral/Paginas/default.aspx > Acesso em 27 ago. 2016.

INPI. Base de Dados do Instituto Nacional da Propriedade Industrial - MARCAS. Disponível em: https://gru.inpi.gov.br/pePI/jsp/marcas/Pesquisa_titular.jsp acessado em 31 mai. 2018.

INPI - Desenho industrial - Mais informações. Disponível em <http://www.inpi.gov.br/menuservicos/desenho/desenho-industrial-mais-informacoes> Acesso em 28 mai. 2018.

INPI. Instrução Normativa $n^{\circ}$ 11-2013 - Estabelece normas e procedimentos relativos ao registro de programas de computador. $\quad$ Disponível em <http://www.inpi.gov.br/legislacao-1/instrucao_normativa_11-2013.pdf> Acesso em 31 mai. 2018.

JUNGMANN, Diana de Mello. BONETTI, Esther Aquemi. Inovação e propriedade intelectual: guia para docente. Brasília: SENAI, 2010. Disponível em < www.inpi.gov.br/sobre/arquivos/guia_docente_iel-senai-e-inpi.pdf > Acesso em 31 mai. 2018.

KOTLER, Philip. Marketing para o século XXI: como criar, conquistar e dominar mercados. Tradução: Bazám Tecnologia e Lingüística: Cristina Bazám. $6^{\circ}$ ed. São Paulo: Futura, 1999.

MARCHI, Leonardo de. Indústria fonográfica e a nova produção independente: o futuro da música brasileira. In: Revista Comunicação, mídia e consumo. São Paulo. Vol. 3 n.7 p. 167 - 182 jul. 2006. Disponível em < revistacmc.espm.br/index.php/revistacmc/article/download/76/77> Acesso em 31 mai. 2018.

MOREIRA, Cínthia Lopes. Direito de marca: a marca e seu registro. Belo Horizonte: Mundo de Cetim, 2006.

REILLY, Robert F.; SCHWEIHS, Robert P. Valuing intangible assets. New York: McGraw-Hill, 1998.

THE ECONOMIST. "Do céu dos cds ao inferno digital" - Via ESTADÃO, caderno Economia \& Negócios. Disponível em <http://economia.estadao.com.br/noticias/geral,do-ceu-dos-cds-ao-infernodigital,10000026896> Acesso em 26. mai. 2018. 
[1] Analista de Propriedade Intelectual na Embrapa

${ }^{[2]}$ Professor da Academia de Propriedade Intelectual do INPI

[3] Advogada de Propriedade Intelectual

\section{PUBLIQUE SEU ARTIGO CIENTÍFICO EM:}

https://www.nucleodoconhecimento.com.br/enviar-artigo-cientifico-para-submissao 